\title{
Estudo ergonômico da expedição de uma empresa de distribuição de medicamentos
}

The ergonomic study of the shipping of a drug distribution company

\author{
Étude ergonomique de l'expédition d'une entreprise de distribution de \\ médicament
}

\author{
Estudio ergonómico del embarque de una empresa distribuidora de la medicina \\ Édson Mauro Carvalho Dutra ${ }^{1}$ \\ Guilherme Linhares Laureano ${ }^{1}$ \\ Ana Regina de Aguiar Dutra ${ }^{1}$
}

Recebido em 01/07/2016; revisado e aprovado em 26/04/2017; aceito em 01/05/2017

DOI: http://dx.doi.org/10.20435/inter.v18i3.1140

\begin{abstract}
Resumo: Este projeto visa abordar um estudo ergonômico da expedição de uma empresa de distribuição de medicamentos, situada no Estado de Santa Catarina, de forma a subsidiar a melhoria nas condições técnicas, ambientais e organizacionais da empresa estudada, ou seja, mostrar as condições e características fornecidas pela empresa aos trabalhadores, quanto aos critérios técnicos, ambientais e organizacionais. A metodologia empregada seguiu as etapas da Análise Ergonômica do Trabalho (AET).
\end{abstract}

Palavras-chave: estudo ergonômico; logística; saúde do trabalhador.

Abstract: This project aims to address the ergonomic study of the shipping of a drug distribution company. It operates throughout the State of Santa Catarina, in order to support the improvement in the technical, environmental and organizational company studied, i.e to show the conditions and characteristics provided by the company to employees, as to technical, environmental and organizational criteria. The methodology used followed the steps of the Ergonomic Work Analysis (EWA).

Key words: ergonomic study; logistics; workers' health.

Résumé: Ce projet a l'intention d'adresser l'étude ergonomique de l'expédition d'une entreprise de distribution de médicament, et opère partout dans l'état de Santa Catarina, pour soutenir l'amélioration de la compagnie technique, de l'environnement et d'organisation étudiée, et montrer les conditions et les caractéristiques fournies par la compagnie aux employés, quant aux critères techniques, environnementaux et organisationnels. La méthodologie a suivi les étapes de l’Analyse Ergonomique du Travail.

Mots-clés: étude ergonomique; logistique; santé des travailleurs.

Resúmen: Este proyecto pretende dirigirse al estudio ergonómico del embarque de una empresa distribuidora de la medicina, y funciona en todas partes del estado de Santa Catarina, a fin de apoyar la mejora de la compañía técnica, ambiental y organizativa estudiada, es decir mostrar las condiciones y características proporcionadas por la compañía a empleados, en cuanto a criterios tecnicos, ambientales y organizacionales. La metodología seguida los pasos de Análisis Ergonómico Trabajo.

Palabras clave: estudio ergonómico; logística; salud de los trabajadores.

\section{INTRODUÇÃO}

O termo Ergonomia, segundo Moraes e Mont'Alvão (2000), foi utilizado, pela primeira vez no ano de 1949, pelo psicólogo inglês K.F.Hywell Murrell, uma vez que pesquisadores da época resolveram formar uma sociedade para estudar os seres humanos em seu ambiente de trabalho - a Ergonomic Reseach Society. Ainda nesse ano, foi fundada a primeira sociedade de ergonomia por membros de diversas classes profissionais, e todos com interesses comuns, ou seja, todos envolvidos com as questões para melhor adaptação do trabalho ao ser humano.

\footnotetext{
${ }^{1}$ Universidade do Sul de Santa Catarina (UNISUL), Palhoça, Santa Catarina, Brasil.
} 
Segunda lida (2005), a data formal do nascimento da Ergonomia foi em 12 de junho de 1949, mas o termo Ergonomia passou a ser integrado em muitos países da Europa, a partir de 1950, substituindo outras denominações como: fisiologia do trabalho e psicologia do trabalho, disseminando-se assim, rapidamente em outros países.

De acordo com Abrahão et al. (2009), no Brasil a Ergonomia surgiu vinculada à Engenharia de Produção e Desenho Industrial, sendo sua atuação voltada para os conceitos baseados na medida humana e na produção de normas e padrões para a população.

Másculo e Vidal (2011) endossam que a Ergonomia atuou, por muito tempo, na análise e ajustes das condições de trabalho, o que envolve esforços e custos consideráveis para operacionalizar tais correções. Contudo tem, atualmente, alargado seu campo de atuação na direção da prevenção, com menores custos e resultados efetivos.

Para que estudos ergonômicos fossem operacionalizados, foi necessária a organização de uma sistemática de investigação, ou seja, nascia assim a metodologia para os estudos ergonômicos, conhecida com a análise ergonômica do trabalho (AET). Segundo lida (2005), a análise ergonômica dos postos de trabalho é parte do estudo das interações entre homem, máquina e ambiente, abrangendo, assim, a análise da tarefa, da postura e dos movimentos do colaborador e também das suas exigências físicas e cognitivas. Vidal (2003) diz que, para garantir a transformação de uma situação de trabalho, emprega-se a metodologia ergonômica, a qual busca assegurar a positividade da transformação por suas características e propriedades de foco, ordenação e sistematicidade. Trata-se de um método abrangente e cuidadoso que nos fornece uma visão muito boa do que acontece num processo de produção ou no uso e manuseio de produtos e equipamentos.

Dul e Weerdmeester (2004) salientam que problemas sociais como: saúde, segurança, conforto e eficiência podem ser solucionados pela ergonomia. Ela também pode auxiliar na prevenção de erros, melhorando assim o desempenho de sistemas produtivos.

Nesse sentido, o fator fundamental para o sucesso dos trabalhadores e para as organizações são as condições de trabalho, investindo assim em saúde e segurança para, então, se alcançarem os níveis de qualidade e de produtividade definidos pelas empresas e mercados.

O referido estudo objetiva mostrar uma intervenção ergonômica em um setor de expedição de cargas de um centro de distribuição de medicamentos, localizado no Estado de Santa Catarina, buscando elaborar recomendações para as melhorias do setor. A problemática deste estudo está relacionada, principalmente, com as atividades de elevação e transporte de cargas, as quais são responsáveis por um número significativo de afastamentos de trabalhadores do seu ambiente de trabalho. A Revista Cipa apontou, em 2016, que as dores lombares são a maior causa de absenteísmo (falta no trabalho) dos brasileiros. Os dados da Previdência Social mostram que, somente no primeiro trimestre de 2016, foram mais de 24 mil afastamentos, em média, 269 trabalhadores afastados por dia por causa de problemas na coluna. Um afastamento a cada cinco minutos.

A NR 17 (BRASIL, 2002) define que o transporte manual de cargas designa todo transporte no qual o peso da carga é suportado inteiramente por um só colaborador, compreendendo o levantamento e a deposição da carga. lida (2005) corrobora ao afirmar que as situações de trabalho que envolvem levantamento de cargas, podem ser classificadas em dois tipos: o levantamento esporádico de cargas, que está relacionado com a capacidade muscular, e o trabalho repetitivo com o levantamento de cargas, no qual entra o fator de duração do trabalho. O autor salienta 
ainda que é necessário, então, conhecer a capacidade humana máxima para levantar e transportar cargas, para que as tarefas e as máquinas sejam corretamente dimensionadas dentro dos limites.

Na mesma direção, Helfenstein Junior, Goldenfum e Siena (2010) concluíram, em seu estudo, que os fatores causais mais diretamente relacionados às lombalgias ocupacionais são os mecânicos, os posturais, os traumáticos e os psicossociais. Afirmam que o trabalho sentado por longas horas, o trabalho pesado, o levantamento de peso, a falta de exercícios físicos e os problemas psicológicos representam alguns dos principais fatores que contribuem para a cronicidade da dor lombar. Para Rose, Mendel e Marras (2013), os distúrbios musculoesqueléticos constituem um grande fardo financeiro para as indústrias, os quais podem ser provenientes da combinação das tarefas de puxar, empurrar e elevar cargas, provocando dores lombares nos trabalhadores.

\section{PROCEDIMENTOS METODOLÓGICOS}

Quanto ao objetivo, o estudo classifica-se como descritivo, pois descreve uma situação de trabalho, com vistas a analisar as condições de trabalho e a apontar recomendações para melhorias. Quanto à natureza, o estudo é qualitativo, uma vez que tem como base a interpretação dos fenômenos e a atribuição de significados, a partir do uso da metodologia ergonômica. Quanto aos procedimentos de coleta e tratamento, fez-se uso das pesquisas: a) bibliográfica, por intermédio dos materiais já publicados; b) documental, a partir de materiais que ainda não receberam tratamentos científicos, por exemplo, documentos da empresa analisada; c) pesquisa de campo, por intermédio de visitas técnicas, entrevistas, registros fotográficos e de filmagens, aplicação de checklists e métodos de avaliação postural, que são instrumentos de rotina da metodologia ergonômica.

A amostra para o presente estudo constituiu-se de sete trabalhadores, vinculados ao setor de expedição de cargas de um centro de distribuição de medicamentos, localizado no Estado de Santa Catarina, com idades variando entre 20 a 49 anos, e com tempos de empresa variando de duas semanas a dois anos e meio. Os trabalhadores têm como atividade principal a separação das mercadorias em gaiolas, para então serem expedidas aos clientes.

O estudo teve como base a metodologia ergonômica (figura 1), que compreende cinco etapas: análise da demanda, análise das condições de trabalho, análise das atividades de trabalho, diagnóstico ergonômico e recomendações para as melhorias. A análise ergonômica do trabaIho é um processo construtivo e participativo para a resolução de um problema complexo que exige o conhecimento das tarefas, da atividade desenvolvida para realizá-las e das dificuldades enfrentadas para atingir o desempenho e a produtividade exigidos (BRASIL, 2002).

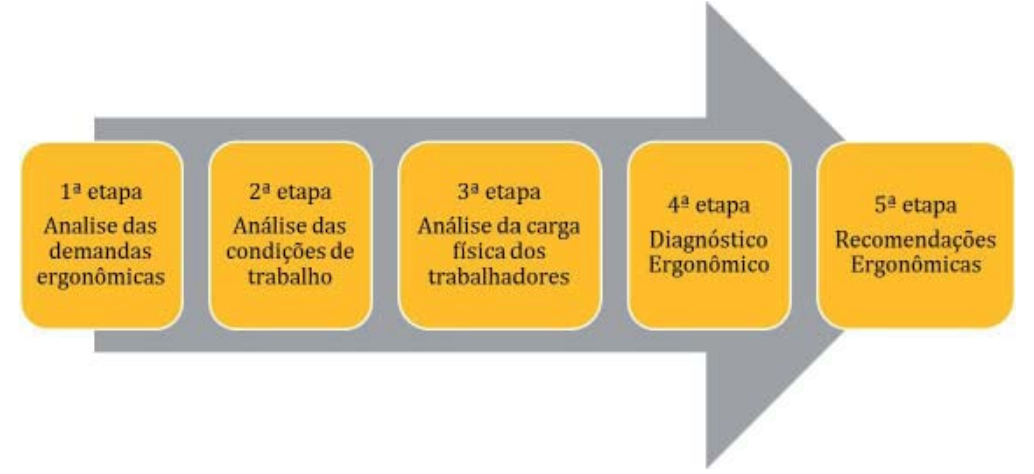

Figura 1- Esquema representativo da metodologia ergonômica (AET) Fonte: Adaptado de Santos e Fialho (1995). 
A partir da figura 1, buscou-se detalhar as etapas da metodologia ergonômica: Na 1a etapa da metodologia, ou seja, na análise ergonômica da demanda, fez-se uma caracterização da empresa e do posto de trabalho, visando elaborar um pré-diagnóstico com as possíveis inadequações ergonômicas. Já na $2 \underline{a}$ etapa, as condições de trabalho foram analisadas, quando se procurou levantar as condições técnicas, ambientais e organizacionais do posto de trabalho em questão. Nesse sentido, fez-se uso de documentos da empresa, observações e entrevistas com os trabalhadores, medições do leiaute, ferramentas e equipamentos.

A 3a etapa compreende a análise das atividades de trabalho, com o estudo das mobilizações físicas dos trabalhadores quando da elevação e transporte de cargas. Para isso se fez uso de registros fotográficos, entrevistas e aplicações da escala de desconforto corporal e o método NIOSH (NATIONAL INSTITUTE FOR OCCUPATIONAL SAFETY AND HEALTH, 1994). A escala de desconforto corporal, proposta pelos autores Corlett e Manenica (1980), procura identificar os desconfortos dos trabalhadores, sinalizando com notas de 1 (dor ausente) a 5 (dores insuportáveis). O uso do método NIOSH é incentivado pela Norma Regulamentadora 17 (Ergonomia) e empregado para calcular o peso máximo recomendado na manipulação manual de cargas. O método NIOSH fundamenta-se em dois índices, o CLR (carga limite recomendada a ser elevada) e o IL (índice de levantamento) (BRASIL, 2002). Para o cálculo do CLR, faz-se uso de seis variáveis: $\mathrm{H}$ - distância horizontal da pega da carga ao ponto médio entre os tornozelos; $\vee$ - altura vertical das mãos em relação ao solo no início da elevação; D- distância vertical percorrida pela carga desde a origem até o destino; A- rotação do tronco do trabalhador ao retirar a carga de um determinado local e depositá-la em outro; e, ainda, duas outras variáveis: F- frequência de levantamento da carga por minuto; I- qualidade da pega da carga. Os resultados das aplicações de ambos os instrumentos podem subsidiar o reprojeto de postos de trabalho e assim evitar riscos de lombalgias devido à manipulação manual de cargas.

Na 4a etapa, estabeleceu-se um diagnóstico das principais patologias ergonômicas existentes na situação de trabalho analisada, que devem merecer uma transformação. Por fim, na 5a etapa, a metodologia busca a elaboração das recomendações ergonômicas, as quais visam eliminar ou reduzir as inadequações ergonômicas identificadas no posto de trabalho.

\section{ESTUDO ERGONÔMICO DO POSTO DE TRABALHO}

\subsection{Análise ergonômica da demanda}

A empresa do estudo atua em mais de $90 \%$ do mercado farmacêutico nacional, possuindo centros de distribuição (CDs) em quase todas as regiões do Brasil, conforme figura 2. Essa estrutura oferece mais de 77 mil $\mathrm{m}^{2}$ de armazenagem, com aproximadamente 12 mil itens entre medicamentos e produtos de higiene e beleza. Nessas regiões, a empresa está presente em mais de 4 mil municípios, atendendo mais de 35 mil farmácias. Os planos de expansão visam atingir 96\% da área de atuação. 


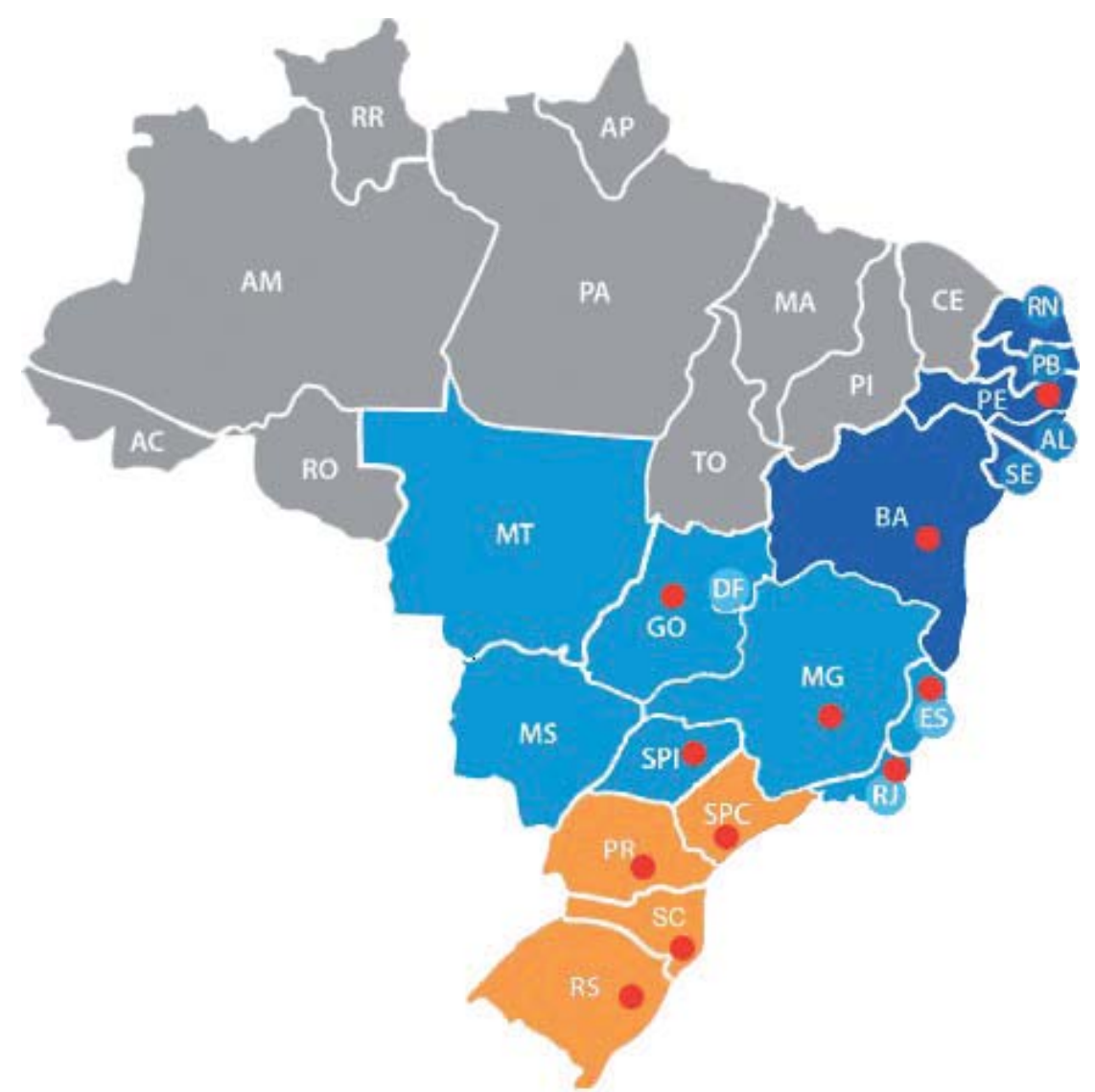

Figura 2- Abrangência de atuação da Empresa

Fonte: Documento da Empresa (2014).

O fluxograma do processo de produção é apresentado na figura 3, para que se possa conhecer a dinâmica do posto de trabalho.

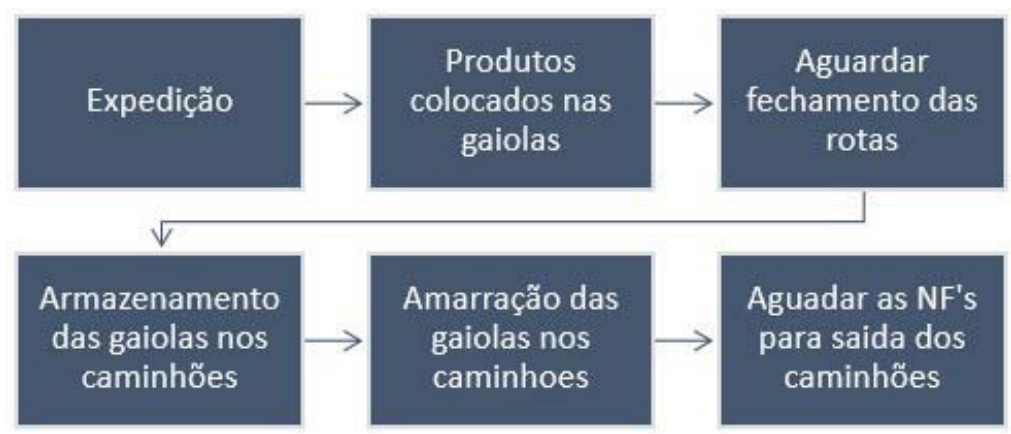

Figura 3 - Fluxograma de produção

Fonte: Autores (2014).

A partir da 1aㅡ etapa da metodologia ergonômica, foi possível estabelecer um pré-diagnóstico do posto de trabalho analisado, apontando prováveis inadequações ergonômicas. Sendo assim, observou-se que uma das inadequações mais crítica são as trocas e envios de alguns produtos para destinos equivocados, em função de um possível cansaço dos trabalhadores, devido às jornadas extensas. Como a jornada acontece no período noturno, o trabalhador pode então ter outra atividade de trabalho durante o dia, o que acarretaria um cansaço físico acumulado. 


\subsection{Análise ergonômica das condições do posto de trabalho}

De acordo com lida (2005), a definição do posto de trabalho consiste na menor unidade produtiva, envolvendo um colaborador em seu local de trabalho. Ele ainda relata que o posto de trabalho pode ser comparado a uma célula, sendo o homem o núcleo da célula. Assim, para que o colaborador realize o trabalho de forma mais sadia e produtiva, será necessário que o posto esteja bem.

Nessa etapa da metodologia ergonômica, apresentam-se algumas informações importantes do posto de trabalho quanto às condições técnicas, ambientais e organizacionais. Quanto às condições técnicas, o leiaute (figura 4) representa o espaço de trabalho do CD e do posto de trabalho analisado (setor de expedição), e que compreende duas docas de $164 \mathrm{~m}^{2}$, onde se expede 140.000 unidades/dia. As rampas de acesso aos caminhões têm 4 m².

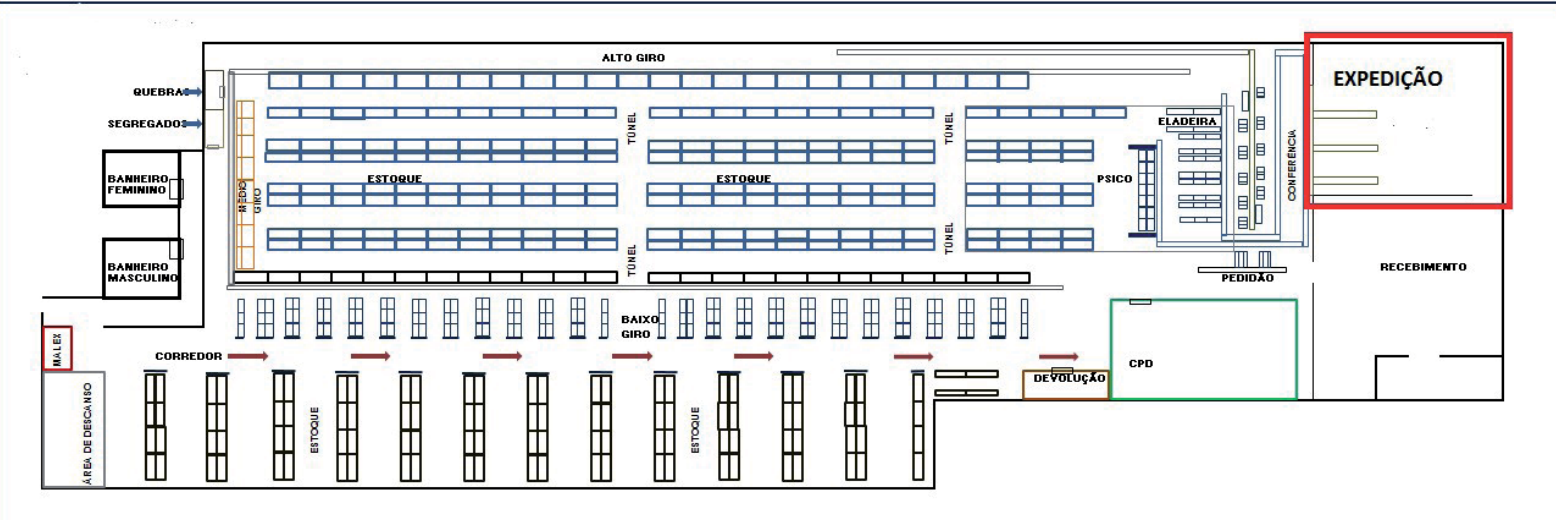

Figura 4 - Layout do CD

Fonte: Autores (2014).

O setor de expedição conta com: a) esteiras- que têm a função de transportar os volumes ao longo do setor; b) gaiolas- são estruturas de $2,5 \mathrm{~m}^{3}$ para armazenar volumes, com dois compartimentos, as quais serão depositadas nos caminhões; c) pallets que têm também a função de armazenar os volumes; d) paleteiras são utilizadas nos deslocamento dos pallets. O setor ainda conta com computadores e scanners, com as funções de registrar os dados dos produtos, quantidades enviadas aos clientes e a emissão de notas fiscais (NFs).

Quanto às condições ambientais do posto de expedição, constatou-se que a iluminação do local é suficiente, segundo a percepção dos trabalhadores. A iluminação nesse local é de extrema importância, pois o trabalho acontece durante a noite e exige atenção. Uma boa iluminação aumenta a produtividade, gera um ambiente mais prazeroso e assegura ainda a segurança dos trabalhadores.

Quanto ao conforto térmico do setor de expedição, a temperatura varia com as estações do ano. No verão, a expedição conta com três grandes ventiladores, além das docas ficarem todas abertas para circulação do ar, proporcionando assim uma temperatura agradável. Já no inverno, o setor de expedição torna-se um local frio, visto que as docas ficam abertas, expostas ao frio e ao vento. Os trabalhadores desse local expressaram satisfação com a temperatura ambiente, somente com apontamentos de insatisfação quando dos meses de inverno. As vantagens, segundo Abrahão et al. (2009), de se buscar o conforto térmico em um ambiente de trabalho são: 
maior rendimento do trabalho, menor índice de acidentes, menor índice de doenças (fadiga, exaustão, desidratação) e melhor entrosamento funcional e social.

Quanto ao conforto acústico, os trabalhadores do setor de expedição sentem-se satisfeitos de uma forma geral. Contudo eles salientam que os bips provenientes do processo de registrar itens e volumes, por meio dos computadores e scanners, acabam provocando certo incômodo e atrapalham na concentração ao realizar a tarefa. Os bips são constantes durante o decorrer da noite. E, ainda, o ruído gerado pelas máquinas de costura do setor de conferência acaba atingindo o setor de expedição, o que prejudica o conforto dos trabalhadores. De acordo com Dul e Weerdmeester (2004), os ruídos provocam interferências nas concentrações que podem ocorrer até mesmo com ruídos em intensidades baixas, e podem apresentar irritabilidade, vertigens, nervosismo, aceleração do pulso, aumento da pressão arterial e surdez.

No quesito condições organizacionais, os trabalhadores do setor de expedição iniciam sua jornada de trabalho às 19 horas, tendo uma hora de intervalo para refeição, totalizando sete horas totais de trabalho. Os horários de trabalho não são fixos, ficando na dependência do volume vendido por dia. A média vendida mensalmente é de 2 milhões de unidades, operando em cinco dias úteis.

Ao entrar na empresa, os trabalhadores recebem capacitação conforme o manual do setor de expedição, esta ação é padrão para todos os CDs situados no Brasil. A empresa apresenta um índice significativo de rotatividade de trabalhadores. Dessa forma, como estratégia para valorizar e reter os trabalhadores, a empresa criou um programa que objetiva proporcionar um crescimento profissional na própria empresa.

A tarefa dos trabalhadores do setor de expedição compreende as etapas de registrar os volumes (são embalagens com diferentes itens), armazenar nas gaiolas, pedir a solicitação das notas fiscais e carregar os caminhões. São 16 caminhões carregados por dia, sendo necessários 20 minutos por caminhão, abastecidos com gaiolas. Salienta-se que, nos dias de maiores vendas, o trabalho é mais acelerado, com isso pode aparecer o cansaço e os trabalhadores estão sujeitos a erros.

A partir da 2a etapa da metodologia, observou-se que a meta a ser atingida, de 2 milhões de unidades vendidas, poderá provocar um grande fluxo de embalagens de mercadorias, as quais deverão ser alocadas nas gaiolas e posteriormente nos caminhões, e com possíveis consequências na ocorrência de erros nos destinos do produto. Os movimentos dos trabalhadores são repetitivos ao desenvolver a tarefa, o que, a longo prazo, pode ocasionar-lhes lesões.

\subsection{Análise ergonômica das atividades de trabalho}

Segundo lida (2005), existe na ergonomia uma grande preocupação com as posturas que são desenvolvidas no trabalho, pois essas posturas fazem com que o trabalhador desenvolva características anatômicas e fisiológicas, sendo estas ligadas às limitações específicas do equilíbrio e obedecendo assim, às leis da Física e da Biomecânica. Por outro lado, far-se-á o indivíduo adotar posturas diferentes diante da tarefa que estiver executando.

Com relação à configuração dos postos de trabalho, devem-se levar em conta as características antropométricas e biomecânicas dos trabalhadores, principalmente as posturas desenvolvidas por esses trabalhadores. Destaca-se:

A postura não tem somente a função de manter o equilíbrio do corpo, ela é também um elemento fundamental da atividade de trabalho. Ela é dinâmica. Resulta de um compromisso 
entre as necessidades da ação, das características das pessoas e de suas condições durante o decorrer da atividade. (ABRAHÃO, 2009, p. 95).

Para avaliar as posturas assumidas pelos trabalhadores e seus impactos na saúde, aplicou-se, primeiramente, a escala de desconforto corporal junto aos trabalhadores do setor de expedição. Os resultados apontaram desconfortos nas regiões das pernas e da lombar, como mostrado na figura 5, muito provenientes do trabalho na posição em pé por tempo prolongado.

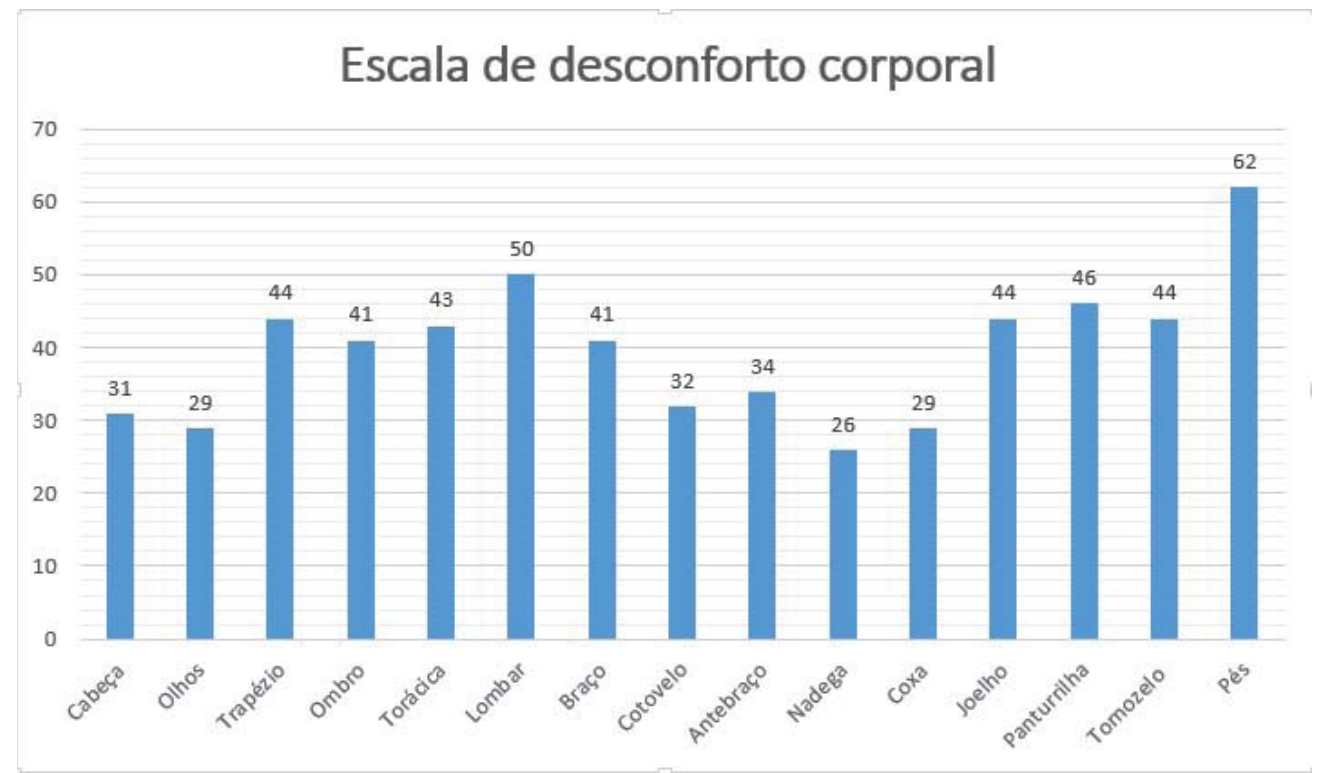

Figura 5 - Resultados a partir da Escala de Desconforto Corporal Fonte: Autores (2014).

Os trabalhadores na tarefa de expedição assumem uma posição em pé durante toda a jornada e uma rotação de tronco de 180으, ocasionando assim desconfortos nas regiões dos pés e da lombar. lida (2005) diz que a lombalgia é a dor na região lombar, é ocasionada pela fadiga da musculatura das costas, na qual o tipo mais comum ocorre devido à permanência durante muito tempo na mesma postura, com a cabeça inclinada para frente.

Quanto à aplicação do método NIOSH, definiram-se dois pontos para análise: gaiolas vazias e gaiolas praticamente cheias de volumes, ambas as situações podem ser consideradas críticas, exigindo do trabalhador posturas de flexão de tronco ou de elevação dos pés. Os volumes são caixas de papelão de diferentes tamanhos, nas quais se armazenam os itens de um pedido de venda. As gaiolas, quando vazias, estão posicionadas a $10 \mathrm{~cm}$ do chão e, quando cheias, ficam a 2,20 m do chão. Os volumes não ultrapassam em média a 1,5 kg. Concluiu-se, a partir do método NIOSH, que os trabalhadores não têm riscos significativos de lesão, contudo é importante salientar que as variáveis rotação de tronco e frequência de elevação (repetitividade) precisam de estudos mais aprofundados, para assim se propor melhorias no posto de trabalho.

\subsection{Diagnóstico e recomendações ergonômicas}

O diagnóstico ergonômico aponta as inadequações presentes no ambiente de trabalho e seus impactos. Cada inadequação exigirá uma recomendação ou encaminhamento de melhoria e, ainda, poderá provocar perdas para o processo produtivo. Cita-se, primeiramente, a perda por 
espera, pois o processo de separação dos itens é feito manualmente e, muitas vezes, o volume de uma rota chega na expedição antes do tempo correto. Com isso, o volume é armazenado embaixo das esteiras, reduzindo o espaço do ambiente de trabalho e deixando produtos parados desnecessariamente. Para esse caso, a recomendação é corrigir o processo de separação dos volumes para os caminhões, diminuindo assim os volumes desnecessários na expedição. Outra perda é por defeito, em função da forma como se armazenam os volumes nas gaiolas e nos caminhões, provocando, muitas vezes, danos aos volumes embalados e às devoluções. A capacitação dos colaboradores ajudaria no entendimento da melhor forma de armazenar e, ainda, dos gastos desnecessários gerados pela devolução.

\section{CONSIDERAÇÕES FINAIS}

As considerações finais deste estudo estão pautadas, principalmente, nas contribuições da metodologia ergonômica, a Análise Ergonômica do Trabalho, como meio de aperfeiçoar os processos produtivos, ao alcançar índices positivos de qualidade e de produtividade dos produtos e/ou serviços prestados pelas empresas, bem como a melhoria das condições de trabalho para assegurar a saúde e a segurança dos trabalhadores, ou seja, para a Ergonomia, os esforços, ao analisar as condições de trabalho e as mobilizações do trabalhador para produzir, são de atender aos critérios de saúde, segurança, qualidade e produtividade, a partir da aplicação da metodologia na direção de melhorar o ambiente de trabalho.

O novo cenário empresarial demanda das empresas, melhores condições de trabalho e desempenhos em termos de qualidade e produtividade. Nesse contexto, o trabalhador saudável é o maior bem econômico de uma empresa, pois só assim se tem chance de assegurar os cumprimentos de metas, prazos e demandas do mercado, competitivo e globalizado.

\section{REFERÊNCIAS}

ABRAHÃO, J.; SZNELWAR, L.; SILVINO, A.; SARMET, M.; PINHO, D. Introdução à ergonomia: da prática à teoria. São Paulo: Edgard Blucher, 2009.

BRASIL. Ministério do Trabalho e Emprego (MTE). Manual de aplicação da Norma Regulamentadora $n$. 17. 2. ed. Brasília: MTE, SIT, 2002. Disponível em: <http://www.ergonomia.ufpr.br/MANUAL_NR_17.pdf>. Acesso em: 4 jan. 2017.

CORLETT, E. N.; MANENICA, I. The effects and measurement of working postures. Applied Ergonomics, Trondheim, v. 11, n. 1, p. 7-16, 1980.

DUL, J.; WEERDMEESTER, B. Ergonomia prática. Tradução de por Itiro lida. 2. ed. rev. e ampl. São Paulo: Edgard Blucher, 2004.

IIDA, I. Ergonomia: projeto e produção. 2. ed. São Paulo: Edgard Blucher, 2005.

HELFENSTEIN JUNIOR, M.; GOLDENFUM, M. A.; SIENA, C. Lombalgia ocupacional. Revista da Associação Médica Brasileira, v. 56, n. 5, p. 583-9, 2010. Disponível em: <http://www.scielo.br/pdf/ramb/v56n5/ v56n5a22.pdf> Acesso em: 3 jan. 2017.

MORAES, A.; MONT'ALVÃO, C. M. Ergonomia: conceitos e aplicações. Rio de Janeiro: Editora 2AB, 2000.

MÁSCULO, F. S.; VIDAL, M. C. Ergonomia: trabalho adequado e eficiente. Rio de Janeiro: Elsevier/ABEPRO, 2011.

NATIONAL INSTITUTE FOR OCCUPATIONAL SAFETY AND HEALTH (NIOSH). Applications manual for the revised NIOSH lifting equation. Cincinnati, OH: U.S. Dept. of Health and Human Services. Public health 
Service, 1994. Disponível em: <https://www.cdc.gov/niosh/docs/94-110/pdfs/94-110.pdf >. Acesso em: 5 jan. 2017.

REVISTA CIPA. Dor nas costas é a principal causa de afastamento do trabalho. 16/07/2016. Disponível em: <http://revistacipa.com.br/dor-nas-costas-e-a-principal-causa-de-afastamento-do-trabalho/>. Acesso em: 3 jan. 2017.

ROSE, J. D.; MENDEL, E.; MARRAS, W. S. Carrying and spine loading. Ergonomics, v. 56, n. 11, p. $1722-$ 1732, 2013. Disponível em: <http://dx.doi.org/10.1080/00140139.2013.835870>. Acesso em: 3 jan. 2017.

SANTOS, N.; FIALHO, F. Manual de análise ergonômica do trabalho. Curitiba: Genesis, 1995.

VIDAL, M. C. Guia para análise ergonômica do trabalho na empresa: uma metodologia realista, ordenada e sistemática. Rio de Janeiro: Virtual Científica, 2003.

\section{Sobre os autores:}

Édson Mauro Carvalho Dutra: Atua na área de Ciências Sociais e Aplicadas. Tecnólogo formado em Logística pela Universidade do Sul de Santa Catarina (UNISUL), Tecnólogo formado em Processos Gerenciais pelo Centro Universitário Leonardo Da Vinci (UNIASSELVI). Cursando Engenharia de Produção na UNISUL. Assistente Acadêmico na Gerência de Ensino, de Pesquisa e de Extensão na UNISUL, onde exerce atividades relacionadas à recepção da Comissão Avaliadora do MEC, para Reconhecimento de Cursos de Graduação da Universidade. E-mail: edsmauroenglog@gmail.com

Guilherme Linhares Laureano: Gestor de produção na empresa Nanovetores S/A. Graduando em Engenharia de Produção na Universidade do Sul de Santa Catarina (UNISUL). E-mail: guilinhares777@gmail.com

Ana Regina de Aguiar Dutra: Graduação em Matemática e mestrado e doutorado em Engenharia de Produção pela Universidade Federal de Santa Catarina (UFSC). Professora titular da Universidade do Sul de Santa Catarina (UNISUL). Tem experiência na área de Engenharia de Produção, com ênfase em Ergonomia, atuando principalmente nos seguintes temas: ergonomia, produtos e processos produtivos, desenvolvimento sustentável, educação. E-mail: aradutra@gmail.com 